\title{
Surgical options for mesothelioma: a narrative review of radical pleurectomy and decortication
}

\author{
Kimberly J. Song ${ }^{1}$, Andrea S. Wolf ${ }^{2}$ \\ ${ }^{1}$ Department of Thoracic Surgery, Mount Sinai Health System, Icahn School of Medicine at Mount Sinai, New York, NY, USA; ${ }^{2}$ Department of \\ Thoracic Surgery, New York Mesothelioma Program, Mount Sinai Health System, Icahn School of Medicine at Mount Sinai, New York, NY, USA \\ Contributions: (I) Conception and design: Both authors; (II) Administrative support: Both authors; (III) Provision of study materials or patients: \\ Both authors; (IV) Collection and assembly of data: Both authors; (V) Data analysis and interpretation: Both authors; (VI) Manuscript writing: Both \\ authors; (VII) Final approval of manuscript: Both authors. \\ Correspondence to: Andrea S. Wolf, MD, MPH. Associate Professor, Department of Thoracic Surgery, Director, New York Mesothelioma Program, \\ Mount Sinai Health System, Icahn School of Medicine at Mount Sinai, One Gustave L. Levy Place, Box 1023, New York, NY 10029, USA. \\ Email: Andrea.Wolf@mountsinai.org.
}

Objective: A discussion on radical pleurectomy with decortication alongside its technical considerations is presented here in accordance with the Narrative Review checklist.

Background: Malignant pleural mesothelioma (MPM) is an aggressive cancer for which there remains no completely standardized treatment regimen, although surgery is an important option for achieving tumor control. There are two predominant approaches to resection in the setting of multimodal treatment: radical pleurectomy/decortication (PD) and extrapleural pneumonectomy (EPP). PD is an increasingly favored surgical approach over the more traditional EPP due to the lower associated perioperative mortality and possibly increased long-term survival. Despite its improved outcomes, PD remains a relatively morbid procedure requiring careful patient selection and postoperative management.

Methods: We present our personal experience and research, supplemented by surgical articles published in the MEDLINE electronic database from January 1990-December 2020. Details of surgical technique, as well as considerations for preoperative and postoperative management are described.

Conclusions: PD is an appropriate surgical approach for debulking MPM in the appropriate patient. All surgical options for mesothelioma require a thorough preoperative evaluation with careful consideration to the individual patient. Unfortunately, there remains limited availability of high quality evidence directly comparing these approaches and the best surgical procedure for MPM remains controversial.

Keywords: Treatment for malignant pleural mesothelioma (MPM); surgery for mesothelioma; extrapleural pneumonectomy (EPP); pleurectomy/decortication (PD)

Received: 03 June 2021; Accepted: 02 November 2021; Published online: 09 November 2021.

doi: 10.21037/asj-21-43

View this article at: https://dx.doi.org/10.21037/asj-21-43

\section{Introduction and background}

Treatment of malignant pleural mesothelioma (MPM) remains difficult as this disease is highly aggressive with a median survival of only 7 months if left untreated (1). Predictors of improved survival include epithelioid cell type and negative resection margins (2), and the successful surgical removal of macroscopic disease sets the stage for multimodal therapy in this deadly malignancy for which there is no standardized treatment algorithm. Additional therapy may include a combination of chemotherapy, radiation, and immunotherapy. After an initial surgical biopsy often performed by video-assisted thoracoscopy (VATS), the two major operations that are typically pursued in patients appropriate for surgical resection are pleurectomy/ decortication (PD) or extrapleural pneumonectomy (EPP). 
Patients with multifocal chest wall invasion, N3 disease, or transdiaphragmatic spread should undergo neoadjuvant treatment, with surgical resection considered for a good response to chemotherapy (3). Additionally, tumors with sarcomatoid or biphasic histology have been associated with poorer survival than epithelioid types, and surgery may not provide benefit in these patients (4).

EPP began as an early surgical treatment for MPM and was initially extremely morbid, with early results reporting perioperative mortality rates as high as $31 \%$ (5). Although this has significantly improved in more recent years, the significant associated morbidity is partially responsible for shifting practice patterns $(6,7)$. The Mesothelioma and Radical Surgery (MARS) feasibility trial, which aimed to compare outcomes of chemotherapy with and without EPP failed to accrue adequate sample size among other significant limitations and a high mortality rate (8). The subsequent Mesothelioma and Radical Surgery 2 (MARS 2) study is recruiting to compare outcomes of chemotherapy with and without PD.

Due to the lack of evidence directly comparing these surgical approaches there are few strong guidelines for management after the diagnosis. Each patient requires careful assessment for physiologic reserve, tumor burden, and individual recovery goals to determine the best course. Regardless of the exact plan, treatment should be expedited at a high-volume center. According to the Surveillance, Epidemiology, and End Results dataset from 1990 to 2004 , cancer-directed surgery is offered to only $22 \%$ of patients outside of specialized centers despite the ability of such surgery to predict longer survival in the context of multimodality therapy (9).

Due to the heterogeneous nature of MPM, the exact extent of resection can vary widely. While PD primarily involves resection of the visceral and parietal pleural surfaces, there is substantial variability in surgeons' perceptions of this term. In an attempt to homogenize the nomenclature, a 2011 consensus report from the International Mesothelioma Interest Group and the International Association for the Study of Lung Cancer suggested the use of the term extended pleurectomy/ decortication to describe a resection including diaphragm and/or pericardium while pleurectomy/decortication was used to describe visceral and parietal pleurectomy without resection of these additional structures (10).

The components of EPP are somewhat more standardized, and include the radical en bloc resection of the lung parenchyma, pleura, diaphragm, and pericardium.
Because of this added morbidity, EPP may require stricter constraints for preexisting pulmonary arterial and right heart pressures and predicted postoperative FEV1 values of at least 1.2 L have been proposed for successful EPP (11). With less effect on cardiopulmonary function and reserve, PD was traditionally reserved for candidates with higher operative risk yet has been associated with lower perioperative mortality and possible increased long-term survival $(12,13)$.

However, given the recurrent and aggressive nature of MPM and its tendency to recur locally (12), the significant morbidity of EPP should be taken into consideration even in patients with excellent baseline functional status. Here we present our technique of radical pleurectomy with decortication including a discussion of its technical considerations. Techniques of EPP and the roles of primary debulking, photodynamic therapy, and hyperthermic intracavitary chemotherapy are beyond the scope of this article but may be discussed elsewhere in this issue. We present the following article in accordance with the Narrative Review reporting checklist (available at https:// asj.amegroups.com/article/view/10.21037/asj-21-43/rc).

\section{Methods}

For this article, we present our personal experience and technique supplemented by articles found using the MEDLINE electronic database. Surgical articles in English from January 1990-December 2020 were reviewed using the keywords "malignant pleural mesothelioma", "extrapleural pneumonectomy", and "pleurectomy decortication". The majority of papers were published after the year 2000; those focusing primarily on medical management or intraperitoneal disease were excluded.

\section{Discussion}

\section{Preoperative evaluation}

As mentioned, both EPP and PD require a thorough evaluation of physiologic reserve and appropriate patient selection is critical, an observation made even by early MPM surgeons (5). Though postoperative outcomes have improved for both procedures, each remains relatively morbid with a mortality rate of $2.2-7 \%(11,12,14)$. Assessment of the patient should include pulmonary function tests (PFTs), cardiac evaluation, positron emission tomography/computed tomography (PET/CT), and baseline performance status. 
$\mathrm{PET} / \mathrm{CT}$ is obtained to evaluate for transdiaphragmatic or contralateral disease, and an MRI may be useful to delineate chest wall or diaphragm invasion (15). Exploratory laparoscopy should be considered if there is radiographic suggestion for transdiaphragmatic spread.

While a formal performance evaluation may not be necessary, an assessment of overall functional status can manage expectations and ensure that treatment goals between the patient and provider are aligned. A recent meta-analysis from our institution collected data from 659 patients and concluded that quality of life (QOL) was diminished after both EPP and PD for at least 6 months after surgery but was worse for EPP patients across both physical and social measures (16). While negative impacts on QOL appear to be less pronounced after PD (17-19), reports are heterogeneous and it remains unclear whether QOL fully returns to baseline.

\section{Operative considerations \& technique}

The primary goal in $\mathrm{PD}$ is to remove all available macroscopic tumor and perform a mediastinal lymph node dissection. Additional goals include achieving maximal lung expansion, preserving cardiopulmonary function, and maximizing postoperative QOL. While some surgeons have suggested pleurodesis might aid dissection in MPM (20), we avoid this in patients who are being considered for resection. We also prefer to avoid placement of tunneled drainage catheters without definitive pathology to avoid potentially seeding the catheter tract or introducing risk of infection.

Immediate preoperative steps include placement of an arterial line, urinary catheter, nasogastric tube, and a thoracic epidural catheter for postoperative pain control. General anesthesia is administered with a double-lumen endotracheal tube for single lung ventilation. As with the majority of our thoracic cases, we perform a flexible bronchoscopy to rule out the presence of any endobronchial lesions.

The patient is placed in lateral decubitus and an S-shaped posterolateral thoracotomy is made through the $5^{\text {th }}$ intercostal space with the incision angled steeply. The surgeon may align the incision with any previous biopsy scars, if appropriate, to remove areas potentially seeded by tumor. The rib may be shingled or excised according to individual preference.

The extrapleural space is often most easily accessed at the thoracotomy site, where a plane can be initiated between the pleural tumor and the remainder of the chest wall. Once developed, a combination of blunt and sharp dissection can be used to carry the dissection in each direction, separating the parietal pleura from the endothoracic fascia with the goal of safely removing all gross disease. Superiorly, dissection is taken to the level of the subclavian vessels where caution is needed to avoid vascular avulsion. Lateral considerations include the azygos and superior vena cava on the right and the aorta and esophagus on the left. Identification of the esophagus is aided by palpating the nasogastric tube within it posteriorly. Anteriorly, the dissection is taken to the hilum where care should be taken to identify and spare the phrenic nerve, whenever possible, as experience and data suggest better postoperative pulmonary and general function $(21,22)$.

Inferiorly, the specimen is mobilized off the diaphragm, with the latter preserved whenever possible. Studies by Batirel and others have demonstrated that removal of the diaphragm is not associated with better survival $(23,24)$ and diaphragmatic preservation is associated with better postoperative lung function (25), which is itself associated with improved QOL in thoracic malignancies (26). If diaphragmatic resection is required, this may be reconstructed with $2 \mathrm{~mm}$ gore-tex dual mesh. We use two separate pieces attached for some portion of the overlap to create a dynamic center to minimize tension (Figure 1).

The tumor is similarly dissected off the pericardium. If pericardial resection is required, this is reconstructed with a $1 \mathrm{~mm}$ gore-tex mesh. Fenestration is required to prevent fluid accumulation with tamponade in the early postoperative period. The fenestrations must be small enough that no portion of the heart, such as the atrial appendage, can herniate as this is another potential source of devastating postoperative complication.

Decortication of the visceral pleura can often be approached when taking down the inferior pulmonary ligament. A large tumor burden tends to accumulate in this location and the dissection facilitates entering the appropriate decortication plane which should be taken around the lung parenchyma and carried down into the fissures and onto the pulmonary arteries. The visceral decortication may result in bleeding or obvious air leaks which can be sutured if necessary. Optimal lung reexpansion prior to closure can help to minimize these.

A lymphadenectomy is performed and three chest tubes are placed (anteriorly, posteriorly, and inferiorly). The thoracotomy is closed in the standard fashion and the patient is extubated before leaving the operating room. If 


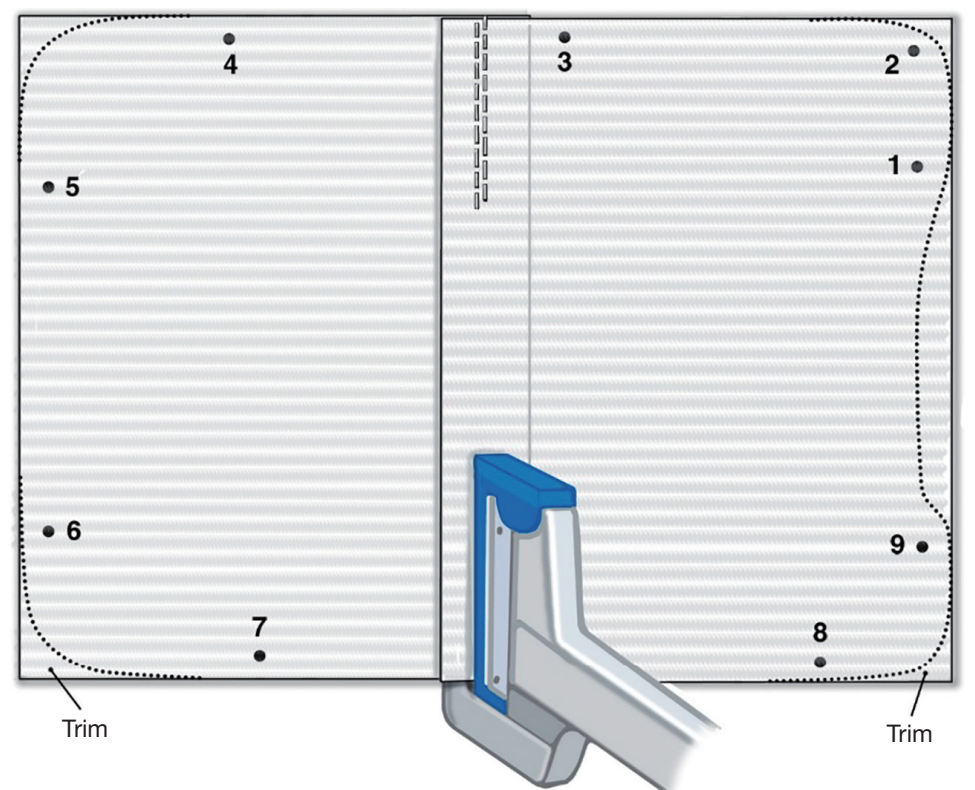

Figure 1 After resection, the diaphragm is reconstructed using two separate $2 \mathrm{~mm}$ PTFE dual-mesh sheets. Numbers 1-9 indicate suggested locations for suturing the mesh. Sutures are brought out through the chest wall and tied using pledgets. From Sugarbarker's Adult Chest Surgery, $3^{\text {rd }}$ ed., by Sugarbaker DJ et al. 2020. Reprinted with permission. PTFE, polytetrafluoroethylene.

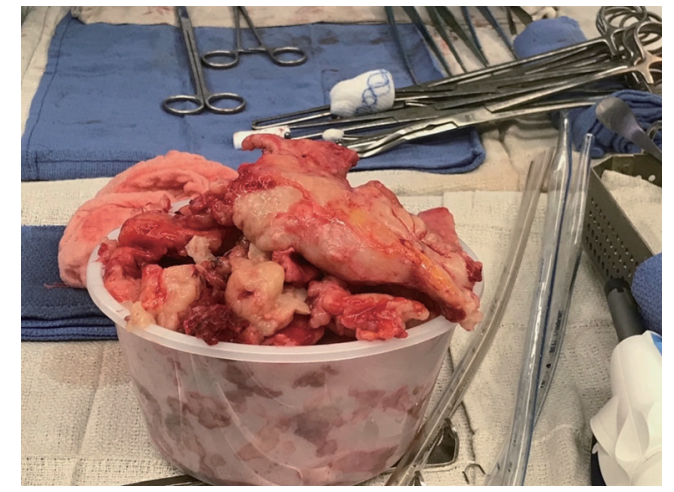

Figure 2 Large pieces of tumor are resected to achieve macroscopically negative margins. Credit Andrea S. Wolf; reprinted with permission.

there is extensive visceral pleurectomy, maintaining positive pressure ventilation for 24-48 hours is one way if improving lung expansion and minimizing blood loss. While positive pressure ventilation may result in loss of volume through the ventilator circuit, gas exchange is usually adequate, as some of the $\mathrm{CO}_{2}$ will diffuse through the tubes. If volume loss is so extensive as to compromise oxygenation, reducing suction on the chest tubes (to $-10 \mathrm{cmH}_{2} \mathrm{O}$ or water seal) is occasionally required. Ultimately, the tumor is removed largely in pieces
(Figure 2), but extensive tumor can be removed with resection deep into the hilum with radical or extended PD (Figure 3).

\section{Postoperative considerations}

Postoperative management is similar to that of other modern thoracic operations. The patient is observed for typical complications such as cardiac arrhythmia, pneumonia, or thromboembolic events. Careful attention to pulmonary toilet is warranted to manage atelectasis and the resolution of any airleaks. Prolonged airleak is relatively common and may require blood patching or discharge from the hospital with a one-way valve. The average patient may expect to stay in the hospital approximately 4-5 days after surgery.

Chemotherapy can be given either before or after surgery as there is a lack of quality data comparing neoadjuvant vs. adjuvant efficacy. Therapy most commonly involves cisplatin/pemetrexed which showed improved progression free survival, overall survival, and therapy response rate in the EMPHACIS trial (27). A systematic review of multimodal treatment approaches reported overall survival ranging 11 to 56.4 months after adjuvant chemotherapy and 8.8 to 35.5 months after induction chemotherapy, though the authors reported limited data regarding completion rates of induction therapy (28). 


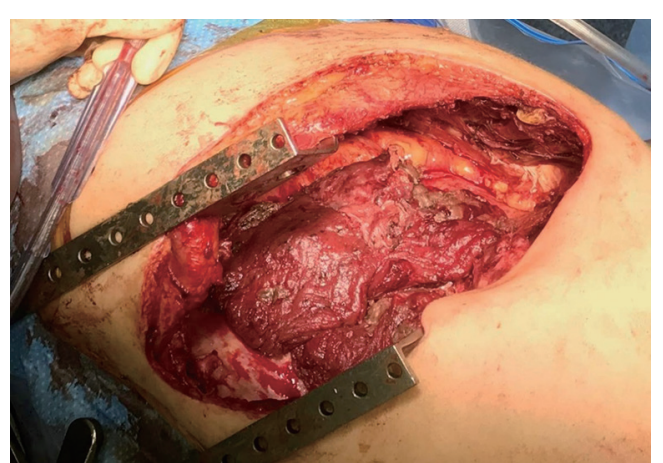

Figure 3 After extended pleurectomy/decortication, all visible disease has been resected from the visceral and parietal pleura. Credit Andrea S. Wolf; reprinted with permission.

\section{Conclusions}

Without a standard treatment algorithm, the management of MPM can follow a number of different paths but surgical resection currently remains a critical aspect, and therapy is likely best managed by at high-volume tertiary referral centers. While controversy over the best surgical option persists, the increased morbidity of EPP, aggressive recurrent nature of MPM, and lasting effects on QOL have led our practice to generally opt for PD whenever possible (7). Careful patient selection, perioperative management, and input from an experienced multidisciplinary team can help minimize the morbidity associated with MPM surgery.

\section{Acknowledgments}

Funding: None.

\section{Footnote}

Provenance and Peer Review: This article was commissioned by the Guest Editors (Abbas E. Abbas and Stacey Su) for the series "Mesothelioma" published in AME Surgical fournal. The article has undergone external peer review.

Reporting Checklist: The authors have completed the Narrative Review reporting checklist. Available at https:// asj.amegroups.com/article/view/10.21037/asj-21-43/rc

Peer Review File: Available at https://asj.amegroups.com/ article/view/10.21037/asj-21-43/prf

Conflicts of Interest: Both authors have completed the ICMJE uniform disclosure form (available at https://asj.amegroups. com/article/view/10.21037/asj-21-43/coif). The series "Mesothelioma" was commissioned by the editorial office without any funding or sponsorship. The authors have no other conflicts of interest to declare.

Ethical Statement: The authors are accountable for all aspects of the work in ensuring that questions related to the accuracy or integrity of any part of the work are appropriately investigated and resolved.

Open Access Statement: This is an Open Access article distributed in accordance with the Creative Commons Attribution-NonCommercial-NoDerivs 4.0 International License (CC BY-NC-ND 4.0), which permits the noncommercial replication and distribution of the article with the strict proviso that no changes or edits are made and the original work is properly cited (including links to both the formal publication through the relevant DOI and the license). See: https://creativecommons.org/licenses/by-nc-nd/4.0/.

\section{References}

1. Sugarbaker DJ, Wolf AS. Surgery for malignant pleural mesothelioma. Expert Rev Respir Med 2010;4:363-72.

2. Sugarbaker DJ, Flores RM, Jaklitsch MT, et al. Resection margins, extrapleural nodal status, and cell type determine postoperative long-term survival in trimodality therapy of malignant pleural mesothelioma: results in 183 patients. J Thorac Cardiovasc Surg 1999;117:54-63; discussion 63-5.

3. Kindler HL, Ismaila N, Armato SG 3rd, et al. Treatment of Malignant Pleural Mesothelioma: American Society of Clinical Oncology Clinical Practice Guideline. J Clin Oncol 2018;36:1343-73.

4. Meyerhoff RR, Yang CF, Speicher PJ, et al. Impact of mesothelioma histologic subtype on outcomes in the Surveillance, Epidemiology, and End Results database. J Surg Res 2015;196:23-32.

5. Butchart EG, Ashcroft T, Barnsley WC, et al. Pleuropneumonectomy in the management of diffuse malignant mesothelioma of the pleura. Experience with 29 patients. Thorax 1976;31:15-24.

6. Sharkey AJ, Tenconi S, Nakas A, et al. The effects of an intentional transition from extrapleural pneumonectomy to extended pleurectomy/decortication. Eur J Cardiothorac Surg 2016;49:1632-41.

7. Wolf AS, Flores RM. Mesothelioma: Live to fight another day. J Thorac Cardiovasc Surg 2018;155:1855-6. 
8. Treasure T, Lang-Lazdunski L, Waller D, et al. Extrapleural pneumonectomy versus no extra-pleural pneumonectomy for patients with malignant pleural mesothelioma: clinical outcomes of the Mesothelioma and Radical Surgery (MARS) randomised feasibility study. Lancet Oncol 2011;12:763-72.

9. Flores RM, Riedel E, Donington JS, et al. Frequency of use and predictors of cancer-directed surgery in the management of malignant pleural mesothelioma in a community-based (Surveillance, Epidemiology, and End Results [SEER]) population. J Thorac Oncol 2010;5:1649-54.

10. Rice D, Rusch V, Pass H, et al. Recommendations for uniform definitions of surgical techniques for malignant pleural mesothelioma: a consensus report of the international association for the study of lung cancer international staging committee and the international mesothelioma interest group. J Thorac Oncol 2011;6:1304-12.

11. Wolf AS, Daniel J, Sugarbaker DJ. Surgical techniques for multimodality treatment of malignant pleural mesothelioma: extrapleural pneumonectomy and pleurectomy/decortication. Semin Thorac Cardiovasc Surg 2009;21:132-48.

12. Flores RM, Pass HI, Seshan VE, et al. Extrapleural pneumonectomy versus pleurectomy/decortication in the surgical management of malignant pleural mesothelioma: results in 663 patients. J Thorac Cardiovasc Surg 2008;135:620-6, 626.e1-3.

13. Taioli E, Wolf AS, Flores RM. Meta-analysis of survival after pleurectomy decortication versus extrapleural pneumonectomy in mesothelioma. Ann Thorac Surg 2015;99:472-80.

14. Flores RM. Surgical options in malignant pleural mesothelioma: extrapleural pneumonectomy or pleurectomy/decortication. Semin Thorac Cardiovasc Surg 2009;21:149-53.

15. Heelan RT, Rusch VW, Begg CB, et al. Staging of malignant pleural mesothelioma: comparison of $\mathrm{CT}$ and MR imaging. AJR Am J Roentgenol 1999;172:1039-47.

16. Schwartz RM, Lieberman-Cribbin W, Wolf A, et al. Systematic review of quality of life following pleurectomy decortication and extrapleural pneumonectomy for malignant pleural mesothelioma. BMC Cancer 2018;18:1188.

17. Martin-Ucar AE, Edwards JG, Rengajaran A, et al. Palliative surgical debulking in malignant mesothelioma. Predictors of survival and symptom control. Eur J Cardiothorac Surg 2001;20:1117-21.
18. Tanaka T, Morishita S, Hashimoto M, et al. Physical function and health-related quality of life in patients undergoing surgical treatment for malignant pleural mesothelioma. Support Care Cancer 2017;25:2569-75.

19. Tanaka T, Morishita S, Hashimoto M, et al. Physical function and health-related quality of life in the convalescent phase in surgically treated patients with malignant pleural mesothelioma. Support Care Cancer 2019;27:4107-13.

20. Pass H, Rice D, Wolf A, et al. The Next Generation of Mesothelioma Surgeons Roundtable Discussion. Semin Thorac Cardiovasc Surg 2016;28:203-20.

21. Ambrogi MC, Bertoglio P, Aprile V, et al. Diaphragm and lung-preserving surgery with hyperthermic chemotherapy for malignant pleural mesothelioma: A 10-year experience. J Thorac Cardiovasc Surg 2018;155:1857-1866.e2.

22. Rena O, Casadio C. Extrapleural pneumonectomy for early stage malignant pleural mesothelioma: a harmful procedure. Lung Cancer 2012;77:151-5.

23. Sharkey AJ, Bilancia R, Tenconi S, et al. The management of the diaphragm during radical surgery for malignant pleural mesothelioma. Eur J Cardiothorac Surg 2016;50:311-6.

24. Batirel HF, Metintas M, Caglar HB, et al. Adoption of pleurectomy and decortication for malignant mesothelioma leads to similar survival as extrapleural pneumonectomy. J Thorac Cardiovasc Surg 2016;151:478-84.

25. Bölükbas S, Eberlein M, Schirren J. Prospective study on functional results after lung-sparing radical pleurectomy in the management of malignant pleural mesothelioma. J Thorac Oncol 2012;7:900-5.

26. Sarna L, Padilla G, Holmes C, et al. Quality of life of long-term survivors of non-small-cell lung cancer. J Clin Oncol 2002;20:2920-9.

27. Vogelzang NJ, Rusthoven JJ, Symanowski J, et al. Phase III study of pemetrexed in combination with cisplatin versus cisplatin alone in patients with malignant pleural mesothelioma. J Clin Oncol 2003;21:2636-44.

28. Marulli G, Faccioli E, Bellini A, et al. Induction chemotherapy vs post-operative adjuvant therapy for malignant pleural mesothelioma. Expert Rev Respir Med 2017;11:649-60.

doi: 10.21037/asj-21-43

Cite this article as: Song KJ, Wolf AS. Surgical options for mesothelioma: a narrative review of radical pleurectomy and decortication. AME Surg J 2023;3:6. 